\title{
Reflexóes sobre o preparo para a docência na pós-graduação em enfermagem
}

\author{
THOUGHTS ON THE PREPARATION OF NURSING GRADUATE STUDENTS \\ FOR UNDERGRADUATE TEACHING
}

REFLEXIONES SOBRE LA PREPARACIÓN PARA LA DOCENCIA

EN EL POSTGRADO EN ENFERMERÍA

Vera Pimentel ${ }^{1}$, Dálete Delalibera Corrêa de Faria Mota ${ }^{2}$, Miako Kimura ${ }^{3}$

\section{RESUMO}

É evidente nos cursos de pósgraduação stricto sensu o enfoque principal na formação para a pesquisa científica e a menor atenção ao preparo para a docência. Trata-se de uma questão relevante, tendo em vista a importância da capacitação de mestres e doutores também para a formação de profissionais da sua área. $\mathrm{O}$ presente texto aborda aspectos do preparo de pósgraduandos em enfermagem para a docência, por meio do Programa de Aperfeiçoamento de Ensino (PAE), oferecido pela Universidade de São Paulo. Relata, ainda, a experiência de alunas que participaram desse Programa, evidenciando a sua contribuição no desenvolvimento de competências para o exercício da docência universitária em enfermagem.

\section{DESCRITORES}

Educação de pós-graduação

em Enfermagem.

Prática do docente

de enfermagem.

Pesquisa em educação

de enfermagem.

\section{ABSTRACT}

It is noticeable the greater focus on scientific production in Graduate courses compared to the attention given to the preparation for teaching practices. This is a relevant issue considering the importance of having Masters and Doctors also prepared to form professionals in their area. This article discusses some aspects of the preparation of Graduate level students enrolled in the Teaching Improvement Program (Programa de Aperfeiçoamento de Ensino, PAE), which the University of São Paulo offers. It also describes the experience of students who participate in the program, emphasizing its contribution to the development of competences for college teaching in Nursing.

\section{KEY WORDS}

Education, nursing graduate.

Nursing faculty practice.

Nursing education research.

\section{RESUMEN}

Es evidente en los cursos de postgrado stricto sensu el enfoque principal en la formación para la investigación científica y la menor atención prestada en la preparación para la docencia. Se trata de una cuestión relevante, teniendo en vista la importancia de la capacitación de maestros y doctores, también, para la formación de profesionales de su área. El presente texto aborda aspectos de la preparación de postgraduados en enfermería para la docencia, por medio del Programa de Perfeccionamiento de Enseñanza (PAE) ofrecido por la Universidad de Sao Paulo. Relata, aun, la experiencia de alumnas que participaron de ese Programa, evidenciando su contribución en el desarrollo de competencias para el ejercicio de la docencia universitaria en enfermería.

\section{DESCRIPTORES}

Educación de postgrado en enfermería.

Práctica de docente de enfermería. Investigación en educación de enfermería.

\author{
1 Enfermeira. \\ Mestranda do \\ Programa de Pós- \\ Graduação em \\ Enfermagem na \\ Saúde do Adulto da \\ Escola de \\ Enfermagem da USP \\ (EEUSP). \\ veratoussaint@ \\ yahoo.com.br \\ 2 Enfermeira. \\ Doutoranda do \\ Programa de Pós- \\ Graduação em \\ Enfermagem na \\ Saúde do Adulto da \\ EEUSP. Bolsista \\ CAPES. \\ dalete.mota@ \\ globo.com \\ 3 Professora Livre- \\ Docente do \\ Departamento de \\ Enfermagem Médico- \\ Cirúrgica da EEUSP. \\ mikimura@usp.br
}




\section{INTRODUÇÃO}

A pós-graduação stricto sensu em Enfermagem no Brasil vem crescendo nos últimos trinta anos e tem contribuído para melhorar a qualificação dos enfermeiros. Os cursos de mestrado e doutorado em Enfermagem concentram-se nas regiões sul e sudeste do país, tal como ocorre na maioria das áreas de conhecimento. A Universidade de São Paulo (USP), localizada na região sudeste, é responsável pela formação de significativo número de mestres e doutores em Enfermagem.

Os propósitos dos cursos de mestrado e doutorado apontados pela Coordenação de Aperfeiçoamento de Pessoal de Nível Superior (CAPES) estão voltados para o desenvolvimento científico-tecnológico, assim como ao preparo para a docência. Claramente, o primeiro propósito é considerado prioritário; contudo, em 1999, reconhecendo a importância da formação de mestres e doutores para o ensino de nível superior, a CAPES passou a incorporar em seu estatuto, o estágio supervisionado em docência ${ }^{(1)}$. Portanto, a ênfase dada à pesquisa deve agora ser compartilhada com o preparo para a docência em cursos superiores.

Observa-se, na atualidade, que os mestres e doutores são mais capacitados para o desenvolvimento de pesquisas, mas estão menos preparados para exigências próprias da educação em nível superior.

Talvez a preocupação com o preparo para a docência pareça ser desnecessária, pois a simples ministração de aulas expositivas, como grande parte dos brasileiros vivencia, não é tarefa demasiadamente difícil. Porém, considerando o atual momento de reflexão sobre a formação superior em Enfermagem, em que mudanças curriculares estão sendo discutidas com base nas diretrizes do Conselho Nacional de Educação e Câmara de Educação Superior, CNE/CES 1.133/2001, e da Lei de Diretrizes e Bases da Educação Nacional (LDB) ${ }^{(2)}$, torna-se importante questionar se os professores estão capacitados para uma prática docente que esteja em consonância com as novas perspectivas que se colocam na educação em enfermagem. Esta é uma questão relevante, quando se verifica que o despreparo dos docentes no ensino universitário, de modo geral, tem sido apontado como um dos fatores que comprometem a qualidade da formação em nível superior ${ }^{(3)}$.

Na Universidade de São Paulo, o estágio supervisionado em docência proposto pela CAPES teve início em 1992, recebendo o nome de Programa de Aperfeiçoamento de Ensino (PAE). O início tímido do Programa foi essencial para o seu desenvolvimento e aprimoramento e, a partir de 1994, assumiu as características que hoje conhecemos ${ }^{(4)}$ e que serão apresentadas adiante, no presente texto.
Apesar do longo período de existência do PAE, poucos relatos daqueles que participaram do Programa estão publicados e quando o são, têm sido divulgados apenas na forma de resumo em eventos locais ou nacionais ${ }^{(5-6)}$. Assim, considerou-se importante relatar a experiência de alunos do PAE, visto que o preparo acadêmico dos professores de nível superior é meta da pós-graduação brasileira e a presença de mestres e doutores qualificados nas universidades é exigência do Ministério de Educação e Cultura (MEC).

\section{PROGRAMA DE APERFEIÇOAMENTO DE ENSINO (PAE)}

O PAE é um programa para alunos de pós-graduação que tem por objetivo principal aprimorar a formação desses alunos para a docência em nível de graduação. O Programa foi regulamentado pela Portaria GR 3347 de 06 de junho de 2002 e modificado pela Portaria GR 3423 de 07 de maio de 2003, destinando-se exclusivamente a alunos de pós-graduação matriculados na Universidade de São Paulo nos cursos de mestrado e doutorado ${ }^{(7)}$. A participação dos discentes no PAE é opcional, excetuando-se aqueles com bolsas CAPES - Demanda Social, para os quais a participação é prevista no Regulamento. Todos os interessados em participar do Programa devem se inscrever na própria Unidade pertinente ao seu curso, no final de um semestre para iniciar no semestre seguinte. A seleção dos candidatos é feita pela Comissão Coordenadora do PAE da Unidade da USP, a partir de critérios estabelecidos de acordo com as normas gerais da Universidade. Os orientadores devem estar cientes sendo, inclusive, necessária a sua autorização para a participação do discente. O aluno com aproveitamento satisfatório no Programa tem direito a um certificado e a créditos especiais definidos pela Comissão de PósGraduação da Unidade( ${ }^{(7)}$.

Atualmente, o Programa é composto por duas etapas: 1) Preparação Pedagógica (PP); 2) Estágio Supervisionado em Docência (ESD). A primeira etapa, PP, visa instrumentalizar o pós-graduando para participar do ensino de graduação. Isso pode ocorrer pela participação do aluno em uma disciplina de pós-graduação que aborde temas referentes à Universidade e ao Ensino Superior, em conjunto de conferências com especialistas em Educação ou pela participação no preparo de material didático, discussões sobre currículo, ementas de disciplinas ou planejamento de cursos, coordenados por professores ${ }^{(7)}$.

A segunda etapa, ESD, é desenvolvida junto a disciplinas específicas da grade curricular da graduação. O pósgraduando participa de seminários, experimentos de laboratório, estudos dirigidos e discussão de tópicos em peque- 
nos grupos, bem como de plantões para esclarecer dúvidas e da avaliação dos graduandos. A carga horária do estágio é de 120 horas no semestre, distribuídas em 6 horas por semana $^{(7)}$.

Em linhas gerais, espera-se que o discente de pós-graduação que participa do PAE desenvolva a capacidade de reflexão e crítica sobre a formação profissional da sua área, em nível de graduação, por meio da atuação efetiva nas diferentes etapas do desenvolvimento de disciplinas específicas. Isto significa envolver-se com o ensino de graduação em toda sua amplitude. Salienta-se que o estágio em docência não significa substituir o docente, mas sim acompanhá-lo ${ }^{(8)}$.

\section{A EXPERIÊNCIA DAS ALUNAS DO PAE NA DISCIPLINA "ENFERMAGEM NA SAÚDE DO ADULTO E DO IDOSO"}

A disciplina Enfermagem na Saúde do Adulto e do Idoso, do Departamento de Enfermagem Médico-Cirúrgica da Escola de Enfermagem da USP, foi o palco da experiência aqui relatada. A disciplina tem por finalidade instrumentalizar o aluno para o cuidado de enfermagem a indivíduos adultos e idosos, no âmbito hospitalar. É oferecida nos dois semestres letivos, podendo matricular-se os alunos que tenham concluído os dois primeiros semestres do curso. A disciplina tem caráter eminentemente teórico-prático, sendo obrigatória no currículo da graduação. A carga horária total é de 165 horas, das quais 100 horas são destinadas a atividades teórico-práticas desenvolvidas em diferentes unidades hospitalares e no laboratório de enfermagem. Cerca de 40 alunos matriculam-se na disciplina em cada semestre sendo que, para as atividades práticas, a classe é dividida em grupos de 6 a 7 alunos. Cada grupo desenvolve o estágio em uma unidade específica, sob supervisão de um docente.

Devido à abrangência de seus objetivos e a diversidade de campos de estágio, foram selecionadas para o Programa, no segundo semestre de 2004, cinco alunas do Programa de Pós-Graduação em Enfermagem na Saúde do Adulto, sendo três de mestrado e duas de doutorado. Quatro alunas participaram da Etapa I (PP) e uma aluna, da Etapa II (ESD).

A etapa PP proporcionou às alunas a oportunidade de acompanhar o planejamento, desenvolvimento e avaliação da disciplina, de participar de reuniões sobre assuntos relativos ao conteúdo programático, de discussões com profissionais dos campos de estágio, visando melhor aproveitamento dos recursos oferecidos para o ensino, além de preparar materiais didáticos e orientar os graduandos nos estudos de casos clínicos.

A participação no preparo de aulas, discussão das estratégias de ensino e elaboração das atividades práticas, que incluíam aulas no laboratório de enfermagem, ocorreu de maneira particular para cada aluna, variando conforme a dis- ponibilidade dos professores e alunos. Durante esta fase, a aluna participante da Etapa II ministrou aula juntamente com a docente.

Na segunda parte da disciplina, desenvolvida nos campos de prática hospitalar, as experiências das pós-graduandas foram bastante diversificadas, incluindo desde atividades de orientação no preparo de estudos de caso e revisão do conteúdo teórico, até a participação na supervisão de alunos nas unidades de estágio. Nesse período, as alunas do PAE tiveram um contato muito próximo com os graduandos e puderam conviver com as dificuldades técnicas e emocionais enfrentadas pelos alunos iniciantes nos campos de prática, assim como discutir e propor estratégias para a melhoria do processo ensino-aprendizagem na disciplina em questão.

Além do entrosamento entre graduandos e pós-graduandos, o contato direto com o corpo docente envolvido na condução da disciplina promoveu momentos de reflexão sobre a educação em enfermagem. Discutiu-se também a implantação de estratégias alternativas de ensino, como por exemplo, a organização de grupos de estudo tendo como tutores os alunos do PAE. Observa-se que, na atualidade, apesar da intenção de aprimorar a formação dos alunos, a introdução de estratégias de ensino inovadoras ainda é lenta e, nesse sentido, os alunos do PAE podem trazer uma contribuição importante.

Resumindo, o pós-graduando tem a oportunidade de acompanhar os graduandos em diferentes atividades, auxiliando-os na articulação de conhecimentos, ao mesmo tempo em que observa como o docente direciona os alunos para o planejamento do cuidado, a implementação dos procedimentos relativos à assistência de enfermagem, estimulando o raciocínio clínico e a atuação interdisciplinar.

\section{REFLEXÕES SOBRE A EXPERIÊNCIA VIVENCIDANO PAE}

As experiências vivenciadas junto aos professores e aos graduandos durante o Programa foram consideradas fundamentais no preparo para a docência de nível superior em enfermagem, especialmente se ambas as etapas do PAE forem cumpridas.

A participação em disciplinas que discutem a problemática do Ensino Superior e da Universidade durante o curso de pós-graduação não é obrigatória. Entretanto, consideramos que uma formação pós-graduada de qualidade exige a aquisição de conhecimentos e habilidades para o ensino, tal como proposto no PAE, uma vez que a formação de professores qualificados para o nível superior é também uma importante função da pós-graduação.

Existem diversas disciplinas oferecidas pela USP e por outras universidades que discutem a educação em nível 
superior, de forma geral e especificamente na enfermagem. Nessa área, estratégias inovadoras, como o ensino à distância, o ensino vinculado à informática e o aprendizado baseado em problema, também conhecido como Problem-Based Learning (PBL) apresentam-se como métodos viáveis para o ensino e que podem contribuir efetivamente para a formação de enfermeiros com competência técnico-científica, críticos e reflexivos.

A experiência vivenciada no PAE mostrou claramente que os alunos de graduação desejam ser participantes ativos do processo ensino-aprendizagem, ou seja, desejam ser mais que meros receptores de conhecimentos para serem construtores da sua própria formação.

Comungando com esta postura, estamos de acordo com as palavras de Freire ${ }^{(9)}$ quando afirma que ...ensinar não é transmitir conhecimentos, mas criar possibilidades para a sua produção ou a sua construção. Podemos afirmar que essa forma de ensinar e aprender identifica-se com a horizontalidade da educação preconizada ${ }^{(9)}$ e cuja característica principal é a interatividade entre aluno e professor e mais, é focada no desenvolvimento da autonomia e responsabi-lidade do aluno perante a sua própria formação. $\mathrm{O}$ paradigma da verticalização, onde o alunado era tido como uma classe submissa e dependente, já não está mais em evidência ${ }^{(1)}$.

Pesquisadores brasileiros ${ }^{(6)}$ relatam a experiência de um estágio em enfermagem, durante o qual empregaram uma estratégia de ensino envolvendo práticas inovadoras, e destacam a importância de tais metodologias no sentido de promover o desenvolvimento da confiança e da autonomia necessárias para que o aluno responda pelo governo do próprio comportamento.

\section{REFERÊNCIAS}

1. Nogueira RA, Pagliuca LMF. Estágio de docência: experiência inovadora na prática de uma doutoranda. Texto Contexto Enferm. 2001;10(1):132-43.

2. Fernandes JD, Xavier IM, Ceribelli MIPF, Bianco MHC, Maeda D, Rodrigues MVC. Diretrizes curriculares e estratégias para implantação de uma nova proposta pedagógica. Rev Esc Enferm USP. 2005;39(4):443-9.

3. Faria JIL, Casagrande LDR. A educação para o século XXI e a formação do professor reflexivo na enfermagem. Rev Lat Am Enferm. 2004;12(5):821-7.

4. Universidade de São Paulo. Pró-Reitoria de Pós-Graduação. Estatística PAE [texto na Internet].São Paulo; 2004. [citado 2004 set. 24].Disponível em: http://www.usp.br/prpg/pro-orga-paeestatist.htm

\section{CONSIDERAÇÕES FINAIS}

A integração entre pós-graduandos e graduandos é uma estratégia positiva no processo ensino/aprendizagem, pois favorece a troca de experiências e permite que o pós-graduando seja inserido no atual contexto da formação profissional na sua área. Com esta perspectiva, a experiência de participar do Programa de Aperfeiçoamento de Ensino revelase de fundamental importância como parte integrante da formação de mestres e doutores. Ao retornarem às salas de aula e ao convívio com os alunos da graduação, os pósgraduandos têm a oportunidade de se confrontar com uma nova perspectiva, face às mudanças nos processos educacionais que vêm ocorrendo em diversos sentidos.

Atividades de preparo para a docência voltadas para os pós-graduandos, como o PAE, estão repletas de oportunidades ímpares de vivenciar a prática do ensino, desde o planejamento das atividades de forma ativa e criativa até a sua execução, permitindo ao aluno, inclusive, perceber e avaliar diferentes estratégias aplicadas no processo ensinoaprendizagem. Programas dessa natureza devem ser incentivados para que maior número de pós-graduandos seja motivado a participar.

A experiência desses alunos na formação para a docência, ao mesmo tempo em que desenvolvem pesquisas, produzem e divulgam conhecimentos da sua área, certamente proporcionará um contingente de mestres e doutores melhor preparados para o enfrentamento dos inúmeros desafios para uma educação de nível superior mais qualificada.

5. Mendes MMR, Freitas MC. Relato de experiência no Programa de Aperfeiçoamento de Ensino (PAE) na Escola de Enfermagem de Ribeirão Preto-USP. In: Programa Científico e Resumos do $8^{\circ}$ Simpósio Brasileiro de Comunicação em Enfermagem; 2002 maio 2-3; Ribeirão Preto. Ribeirão Preto: EERP/USP; 2002. p. 190.

6. Rodrigues MSP, Leitão GCM. Estágio curricular supervisionado com ênfase no desenvolvimento da autonomia e da responsabilidade. Texto Contexto Enferm. 2000;9(3):216-29.

7. Universidade de São Paulo. Pró-Reitoria de Pós-Graduação. Programa de Aperfeiçoamento de Ensino [texto na Internet]. São Paulo; 2005. [citado 2005 jun. 30]. Disponível em: http://www. usp.br/prpg/pro-orga-pae.htm.

8. Universidade de São Paulo. Instituto de Matemática e Estatística. Pontos para reflexão sobre o estágio de docência [texto na Internet].São Paulo; 2004. [citado 2004 set. 24].Disponível em: http://www. ime.usp.br/ song/diretor/estagio-docenciasbpc.html

9. Freire P. Pedagogia da autonomia. São Paulo: Paz e Terra; 2004. 